\title{
Investigating the Properties of CIS Absorber Layer by Using the Spray Coating Method
}

\author{
Chien-Chen Diao, ${ }^{1}$ Cheng-Fu Yang, ${ }^{2}$ Chia-Ching Wu, ${ }^{1}$ Wen-How Lan, ${ }^{3}$ and Yen-Lin Chen ${ }^{2}$ \\ ${ }^{1}$ Department of Electronic Engineering, Kao Yuan University, Kaohsiung 82151, Taiwan \\ ${ }^{2}$ Department of Chemical and Materials Engineering, National University of Kaohsiung, Kaohsiung 81148, Taiwan \\ ${ }^{3}$ Department of Electrical Engineering, National University of Kaohsiung, Kaohsiung 81148, Taiwan \\ Correspondence should be addressed to Cheng-Fu Yang; cfyang@nuk.edu.tw
}

Received 18 September 2013; Accepted 1 October 2013

Academic Editor: Teen-Hang Meen

Copyright (C) 2013 Chien-Chen Diao et al. This is an open access article distributed under the Creative Commons Attribution License, which permits unrestricted use, distribution, and reproduction in any medium, provided the original work is properly cited.

\begin{abstract}
The CuInSe $e_{2}$ absorber layers were deposited on Mo/glass substrates by using the spray coating method (SCM). At first, the CIS powder was ground into nanoscale particles; then the $6 \mathrm{wt} \%$ CIS particles were dispersed into isopropyl alcohol (IPA) to get the solution for SCM. $0.05 \mathrm{~mL}$ CIS solution was sprayed on the $2 \mathrm{~cm} \times 1 \mathrm{~cm} \mathrm{Mo/glass} \mathrm{substrates,} \mathrm{and} \mathrm{then} \mathrm{the} \mathrm{CIS} \mathrm{solution} \mathrm{films} \mathrm{were}$ annealed in a selenization furnace under different parameters. At first, the extra $0.2 \mathrm{~g}$ Se was put in the furnace, the selenization time was $5 \mathrm{~min}$, and the selenization temperature was changed from $450^{\circ} \mathrm{C}$ to $600^{\circ} \mathrm{C}$. After finding the better selenization temperature of $550^{\circ} \mathrm{C}$ and setting the selenization time at $5 \mathrm{~min}$, the selenization process was set at $550^{\circ} \mathrm{C}$ and the extra Se content was changed from $0 \mathrm{~g}$ to $0.6 \mathrm{~g}$. The influences of the selenization temperature and extra Se content on the surface and cross-section morphologies, crystallization, hall mobility, and carrier concentration and resistivity of the CIS absorber layers were well investigated in this study.
\end{abstract}

\section{Introduction}

The quest for new energy to replace the present consumed materials, for example, oil, finding the sustainable sources is one of the major concerns of the present day industrial society. Because photovoltaic (PV) solar energy can serve as a decentralized source of electricity, it is a key sector in this quest. Crystalline silicon solar cells have excellent efficiencies; however, there are serious bottlenecks for this technique with respect to future large-scale applications both from an economical as well as from an ecological point of view. Thus, the thin film silicon solar cells are considered as the main option for large-scale energy applications in the foreseeable future [1-3]. The use of polycrystalline CuInSe (CIS) and $\mathrm{CuIn}_{1-x} \mathrm{Ga}_{x} \mathrm{Se}_{2}$ (CIGS) thin films as the absorber materials for thin film solar cells is another choice and allows easier commercial production because of their appropriate band gap values (e.g., 1.018-1.701 eV, depending on the compositions) and high absorption coefficient in the visible light and near-infrared. Most investigated CIS and CIGS absorber layers are in the polycrystalline structures $[4,5]$.
The CIS or CIGS absorber layers are mainly deposited by various vacuum methods. Sputtering is one of the most popular vacuum methods to deposit CIS or CIGS absorption layers with high quality [6], and molecular beam epitaxy (MBE) is another important process to deposit CIS or CIGS absorption layers [7]. The coevaporation process can be used to fabricate the highly efficient CIS absorber layers and solar cells [8]. However, the most important process for preparing the CIS or CIGS absorber layers is the using twostep processes, sputtering and selenization [9].

The nonvacuum method is the cheapest and the easiest to deposit the CIS and CIGS absorber layers on an industrial scale. $\mathrm{Gu}$ et al. used the $\mathrm{CuCl}_{2} \cdot 2 \mathrm{H}_{2} \mathrm{O}, \mathrm{GaCl}_{3}$, and $\mathrm{Se}$ as the as raw materials; ethylenediamine was used as solvent, and the solvothermal method was used to form the CIGS powders [10]. The spray coating method (SCM) is a very important non-vacuum deposition method to fabricate the thin films because it is a relatively simple and inexpensive non-vacuum deposition method for large-area coating. In the past, we had successfully investigated a modified spray pyrolysis method to deposit the high efficiency Li-doped $\mathrm{NiO}$ 
thin films [11]. As we know, fabricating the CIS and CIGS absorber layers in a non-vacuum process is an important issue for lowering down the fabrication price. However, only few efforts have been made to systematically investigate the CIS and CIGS absorber layers by a SPM method. In this research, the $\mathrm{CuInSe}_{2}$ was ground into nano-scale powers, and SPM method was used to develop the CIS absorber layers. The effects of the different selenization parameters on the physical and electrical properties of the CIS absorber layers, including the surface morphology, crystallinity, carrier mobility, carrier concentration, and resistivity, were well investigated.

\section{Experimental}

High purity $\mathrm{CuInSe}_{2}$ was formed using hydrothermal process by Nanowin Technology Co., Ltd. Because the CIS powder was aggregated into microscale particles and the average particle sizes were approximately $3-8 \mu \mathrm{m}$, it could not be used as the source materials to form the CIS absorber layers as the spray coating method (SCM) was used. After finding the optimum grinding time and KD1 content, the CIS powder was ground into nano-scale, and it had the average particle sizes approximately $40-80 \mathrm{~nm}$. Then, the $6 \mathrm{wt} \%$ CIS particles were dispersed into isopropyl alcohol (IPA) to get the solution for SPM to prepare the CIS absorber layers.

The organic/CIS composite films were formed by SCM on Mo/glass, and then the organic/CIS composite films were annealed for $5 \mathrm{~min}$ by using the rapid temperature annealing (RTA) process in selenization furnace (the chamber size is $5 \mathrm{~cm} \times 5 \mathrm{~cm} \times 4 \mathrm{~cm}$ ) under different annealing parameters to remove the used organic and crystallize the CIS absorber layers. The selenization temperature was changed from $450^{\circ} \mathrm{C}$ to $600^{\circ} \mathrm{C}$, and the extra $0.0 \sim 0.6 \mathrm{~g}$ Se was put in the furnace during the selenization process. After selenization process, the crystalline structure was examined by using Xray diffraction $(\mathrm{XRD})$ pattern, and the surface morphology and cross-section observations of the CIS absorber layers were examined by using the field-emission scanning electron microscope (FE-SEM), respectively. The electrical resistivity and the Hall-effect coefficients were measured using a BioRad Hall setup.

\section{Results and Discussion}

The XRD patterns of the CIS absorber layers as a function of selenization temperature were first investigated, the extra Se content in the selenization furnace was $0.2 \mathrm{~g}$, and the results are shown in Figure 1. The mainly crystalline peak of the CIS absorber layers is the (112). Even though selenization temperature was raised from $450^{\circ} \mathrm{C}$ to $600^{\circ} \mathrm{C}$, all (112) peaks revealed in Figure 1 were situated at $2 \theta=$ $26.66^{\circ}$. This result suggests that even when $600^{\circ} \mathrm{C}$ is used as selenization temperature, the lattice constants of the CIS absorber layers have no apparent change. Figure 1 also shows that the secondary CuSe phase was observed in the $600^{\circ} \mathrm{C}$ selenized CIS absorber layers. As the CIS absorber layers are used to fabricate the thin film solar cells, the formation of secondary phases will degenerate the efficiency. This result

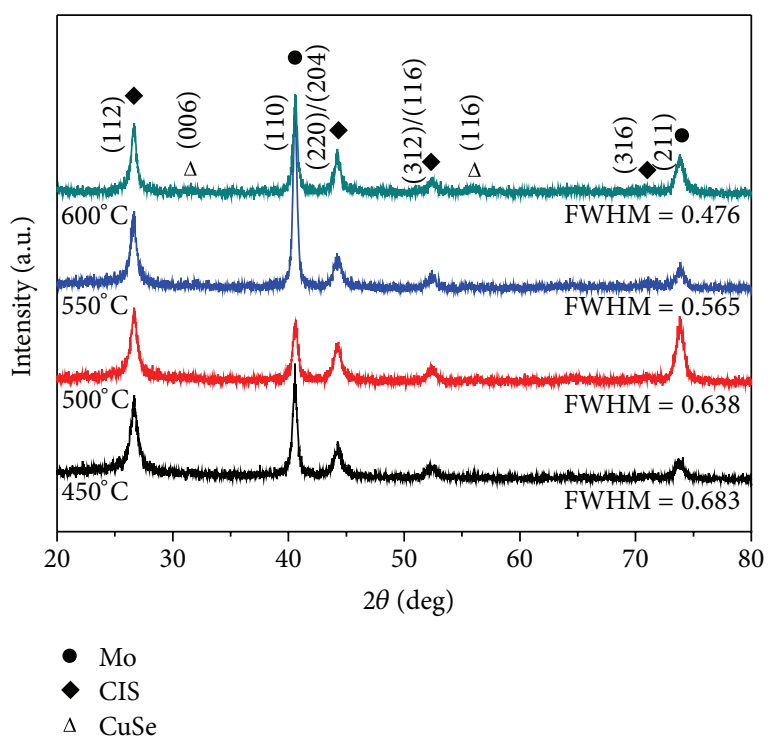

FIGURE 1: XRD patterns of the CIS absorber layers as a function of selenization temperature, the extra Se content was $0.2 \mathrm{~g}$.

suggests that $600^{\circ} \mathrm{C}$ is not suitable to be used as selenization temperature because the secondary phase is formed. The full width at half maximum (FWHM) value of the (112) peak of the CIS absorber layers was $0.683,0.638,0.565$, and 0.476 as the selenization temperature was $450^{\circ} \mathrm{C}, 500^{\circ} \mathrm{C}, 550^{\circ} \mathrm{C}$, and $600^{\circ} \mathrm{C}$, respectively. Also, the relative diffraction intensity of (112) peak had no apparent change as the selenization temperature increased from $450^{\circ} \mathrm{C}$ to $600^{\circ} \mathrm{C}$, as indicated by the XRD patterns shown in Figure 1. These results suggest that CIS absorber layers selenized at higher temperature have the better crystalline structure and the defects in the CIS absorber layers decrease with increasing selenization temperature. This is because as higher temperature is used to treat on the CIS absorber layers, the number of thin film defects decreases and the crystallization of the CIS absorber layer is improved, then the FWHM value decreases.

The surface morphologies of the CIS absorber layers by using extra $0.2 \mathrm{~g}$ Se in selenization furnace and under different selenization temperatures are shown in Figure 2, which indicates that as the selenization temperature changes, the surface morphologies apparently change as well. Evidently, the selenization temperature has a significant effect on the CIS absorber layers' surface morphologies. Selenized at $450^{\circ} \mathrm{C}$, a porous structure was observed, the small CIS particles aggregated into microscale particles (not grain growth), and the average particle sizes were approximately $30-55 \mu \mathrm{m}$. Selenized at $500^{\circ} \mathrm{C}$, a more densified structure with nano-scale particles was observed. These results suggest that $450^{\circ} \mathrm{C}$ and $500^{\circ} \mathrm{C}$ are not high enough to improve the densification and grain growth of the CIS absorber layers, and a roughness surface was observed. When the $550^{\circ} \mathrm{C}$ and $600^{\circ} \mathrm{C}$ were used as the selenized temperatures, the roughness and densification were apparently improved even only nano-scale particles were observed. Comparing the SEM micrographs shown in Figure 2, the grain growth is inhibited 


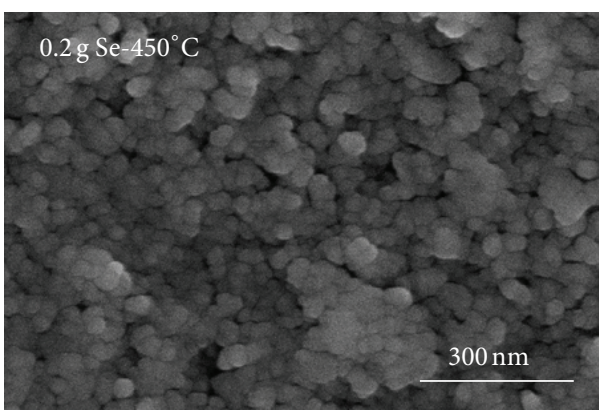

(a)

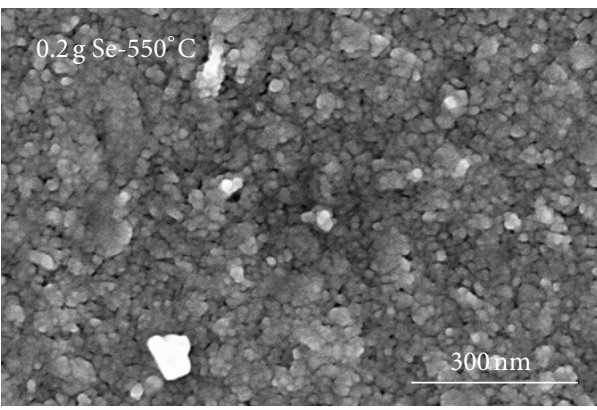

(c)

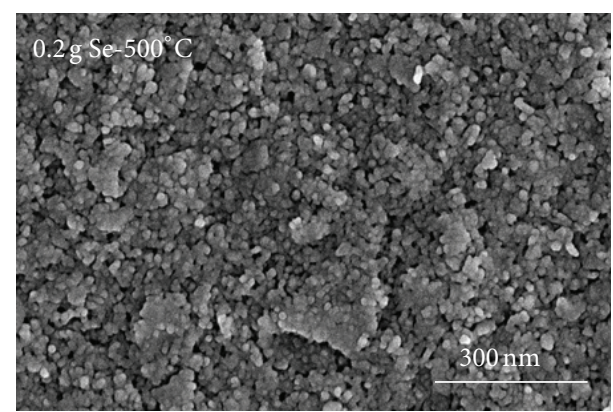

(b)

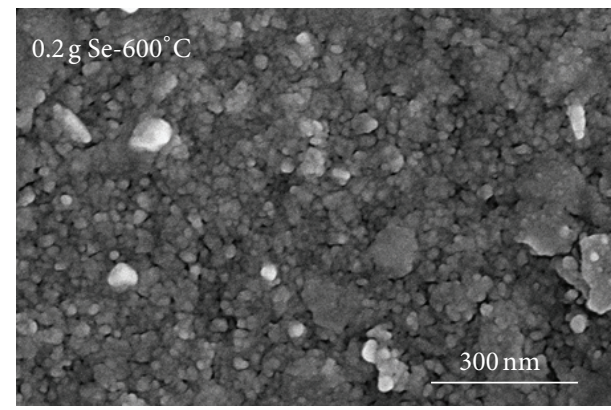

(d)

FIGURE 2: Surface morphologies of the CIS absorber layers as a function of selenization temperature the extra Se content was $0.2 \mathrm{~g}$.

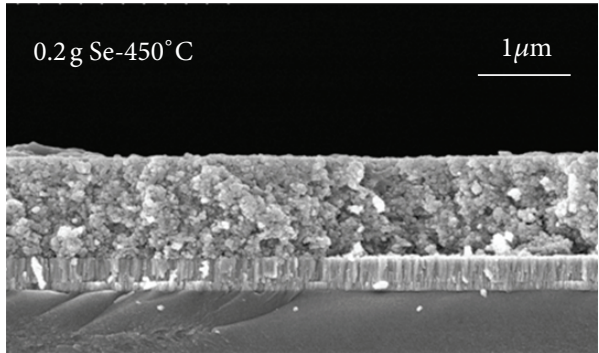

(a)

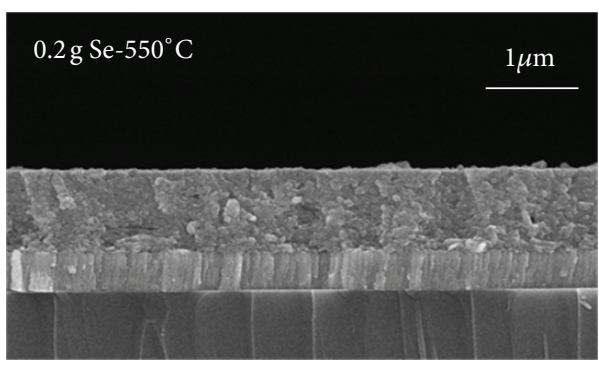

(c)

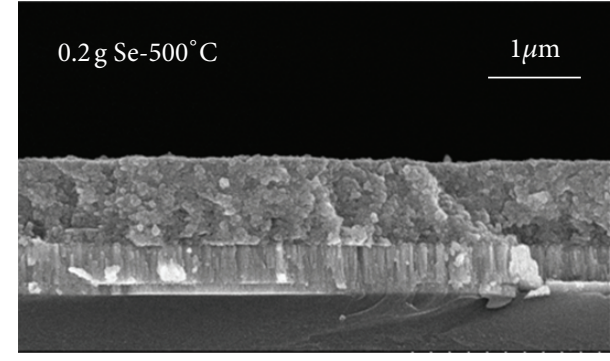

(b)

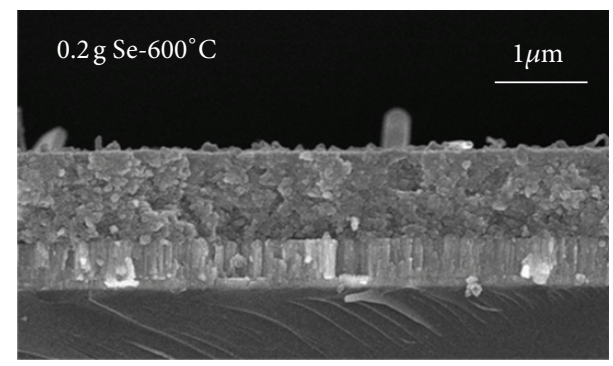

(d)

FIGURE 3: Cross-section observations of the CIS absorber layers as a function of selenization temperature the extra Se content was $0.2 \mathrm{~g}$.

by using the extra $0.2 \mathrm{~g}$ Se in selenized furnace, which will be proved in Figures 6 and 7.

The cross-section observations of the CIS absorber layers as a function of selenization temperature are shown in Figure 3; the extra Se content was $0.2 \mathrm{~g}$. As Figure 3 shows, the thicknesses of the CIS absorption layers were around $900 \sim 1000 \mathrm{~nm}$. This result proves that we can deposit the
CIS absorption layers with uniform thickness by using the spray coating method. The cross-section morphologies also show that the pores and undensified structures are really observed in the $450^{\circ} \mathrm{C}$ - and $500^{\circ} \mathrm{C}$-selenized CIS absorption layers and the densified structures are also really observed in the $550^{\circ} \mathrm{C}$ - and $600^{\circ} \mathrm{C}$-selenized CIS absorption layers. 


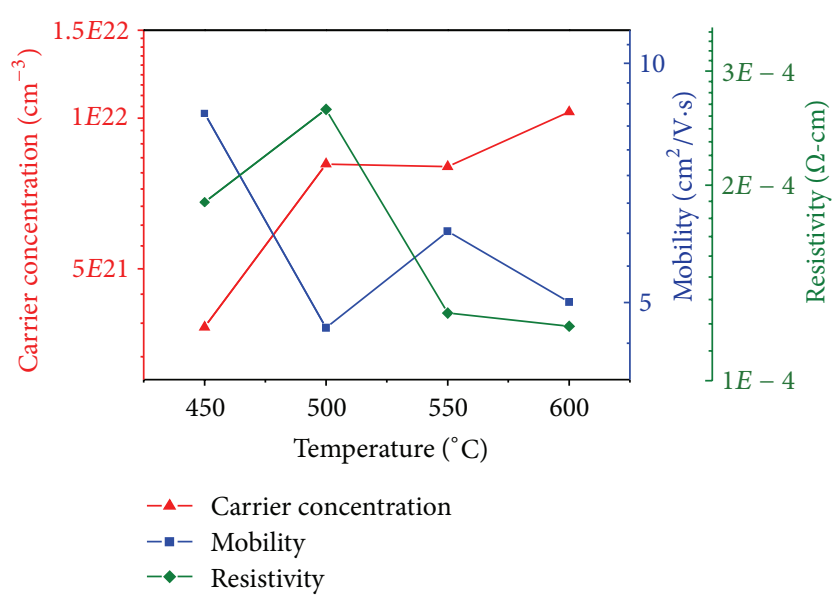

FIgURE 4: Resistivity $(\rho)$, hall mobility $(\mu)$, and carrier concentration $(n)$ of the CIS absorber layers as a function of selenization temperature the extra Se content was $0.2 \mathrm{~g}$.

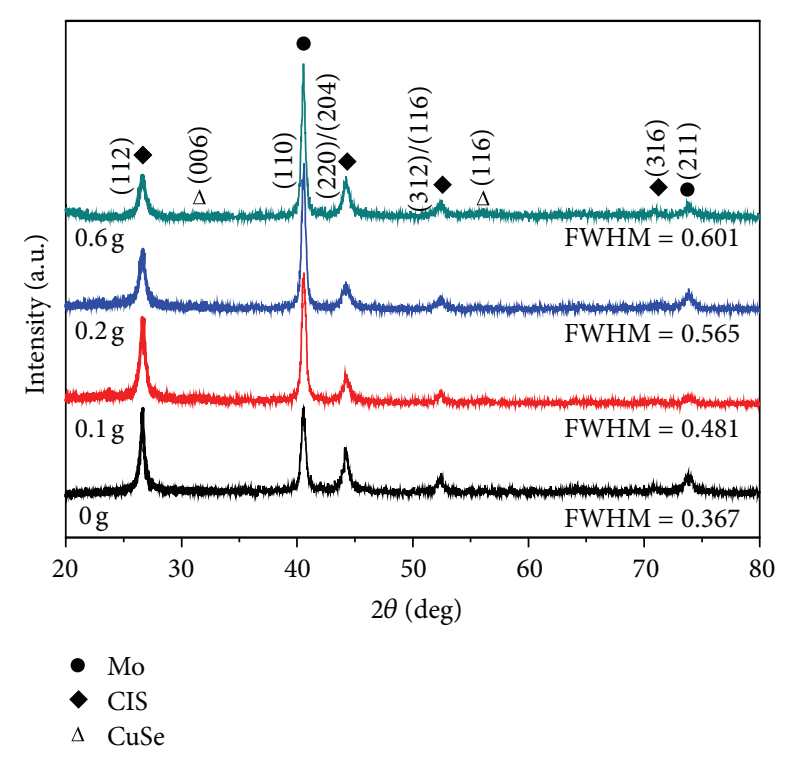

FIGURE 5: XRD patterns of the CIS absorber layers as a function of extra Se content; the selenization temperature was $550^{\circ} \mathrm{C}$.

Figure 4 shows the dependence of electrical properties on selenization temperature of the CIS absorber layers. When the CIS absorber layers are deposited on a glass substrate by using SCM and selenization process, many defects result and inhibit electron movement. As the different selenization temperatures are used during the selenization process, two factors are believed to cause an increase in the carrier mobility of the CIS absorber layers. First, the higher selenization temperature enhances the densification and crystallization, which will decrease the numbers of defects and pores in the CIS absorber layers that will cause the decrease in the inhibiting of the barriers electron transportation [12]. Second, as the selenization temperature is too high and extra Se is used, the secondary phase of the CIS absorber layers will appear because of the vaporization of Se and or the diffusion of extra Se into the CIS absorber layers. In this study, the carrier concentration increased with increasing selenization temperature and reached a maximum of $1.03 \times 10^{22} \mathrm{~cm}^{-3}$ at $600^{\circ} \mathrm{C}$. Thus, the mobility had no apparent trend with the variation of selenization temperature and had a maximum of $8.64 \mathrm{~cm}^{2} / \mathrm{V} \cdot \mathrm{s}$ at $450^{\circ} \mathrm{C}$. The resistivity of the CIS absorber layers is proportional to the reciprocal of the product of carrier concentration $n$ and mobility $\mu$ :

$$
\rho=\frac{1}{n e \mu} .
$$

Both the carrier concentration and the carrier mobility contribute to the conductivity. The minimum resistivity of the CIS absorber layers at a selenization temperature of $600^{\circ} \mathrm{C}$ is mainly caused by the carrier concentration being at its maximum.

The $550^{\circ} \mathrm{C}$ deposited CIS absorber layers have acceptable characteristics, including smaller FWHM value (Figure 1), no secondary phase formed (Figure 1), acceptable carrier concentration and carrier mobility (Figure 4), and smaller resistivity (Figure 4). For that we used $550^{\circ} \mathrm{C}$ as the selenization temperature to develop the characteristics of the CIS absorber layers under different extra Se content used during the selenization process. The XRD patterns of the CIS absorber layers as a function of extra Se content were also investigated, and the results are shown in Figure 5. As extra Se content was $0.0 \mathrm{~g}, 0.1 \mathrm{~g}, 0.2 \mathrm{~g}$, and $0.6 \mathrm{~g}$, the (112) peak revealed in Figure 5 was situated at $2 \theta=26.64^{\circ}, 26.60^{\circ}$, $26.66^{\circ}$, and $26.68^{\circ}$, respectively. Figure 5 also shows that the secondary CuSe phase was observed as extra Se content was $0.6 \mathrm{~g}$. This result suggests that too much extra Se content is not necessary because the secondary phase is formed. The FWHM value of the (112) peak of the CIS absorber layers was $0.367,0.481,0.565$, and 0.601 as extra Se content was $0.0 \mathrm{~g}$, $0.1 \mathrm{~g}, 0.2 \mathrm{~g}$, and $0.6 \mathrm{~g}$, respectively. Except that the FWHM value increased, the relative diffraction intensity of (112) peak also critically decreased as extra Se content increased from $0.0 \mathrm{~g}$ to $0.6 \mathrm{~g}$, as indicated by the XRD patterns shown in Figure 5. This is because as extra Se content is used, more Se will vaporize during the selenization process to inhibit the grain growth, then the FWHM value increases, and the relative diffraction intensity of (112) peak decreases.

Figure 6 shows the surface morphologies of the CIS absorber layers as a function of extra Se content, the selenization temperature was $550^{\circ} \mathrm{C}$, and the results in Figure 6 have large difference as the different extra Se content was added in the selenization furnace. As no extra Se was added in the furnace $(0.0 \mathrm{~g})$, the grain growth and roughness surface were really observed. The surface morphologies shown in Figure 6 apparently revealed that the grain sizes of the CIS absorber layers apparently decreased with increasing extra Se content. As extra $0.2 \mathrm{~g}$ Se was used, even the densified and flat surfaces were observed, and the grain growth in the CIS absorber layers was inhibited. As extra $0.6 \mathrm{~g}$ Se was used, the porous and small grain structure was obtained. This result suggests that as selenized process is used, the extra Se content is important to control the characteristics of the CIS absorber layers. These results suggest that CIS absorber layers selenized 


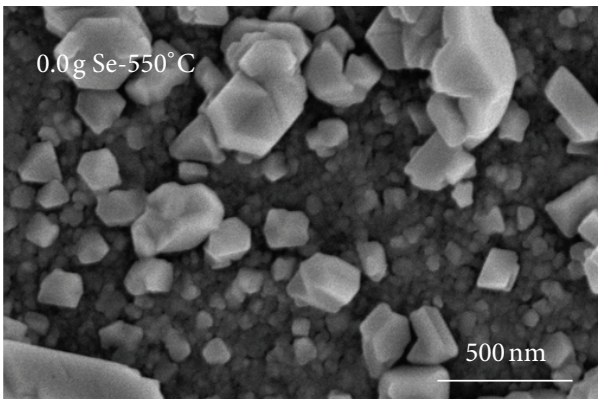

(a)

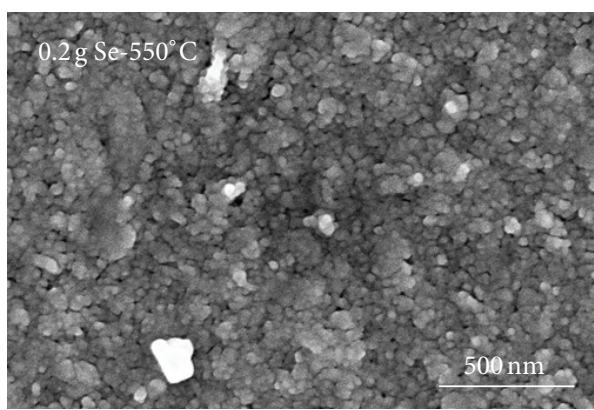

(c)

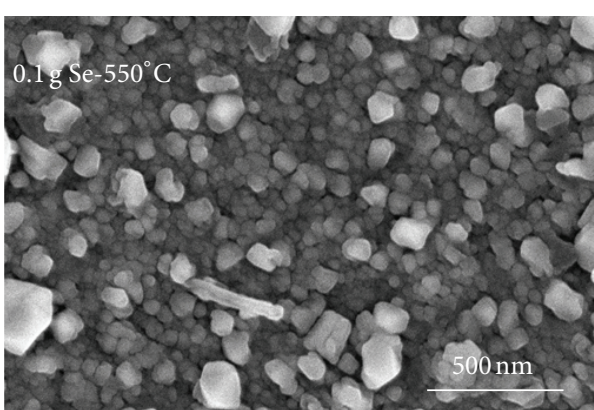

(b)

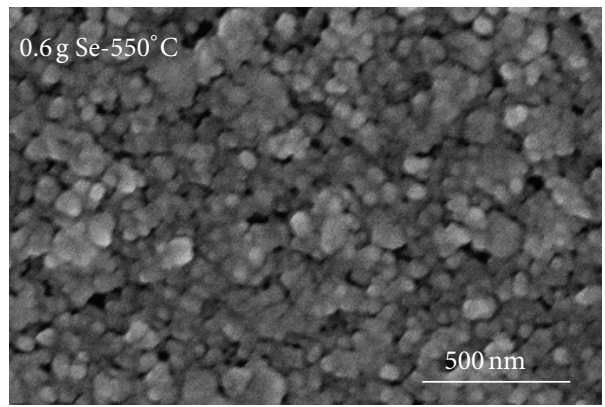

(d)

FIGURE 6: Surface morphologies of the CIS absorber layers as a function of extra Se content, the selenization temperature was $550^{\circ} \mathrm{C}$.

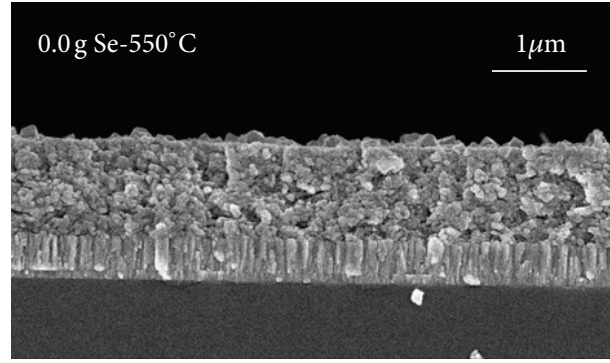

(a)

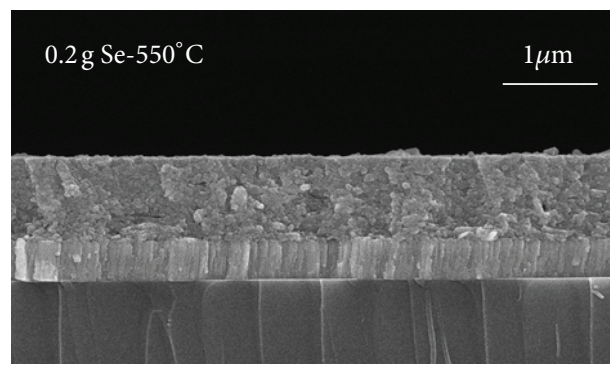

(c)

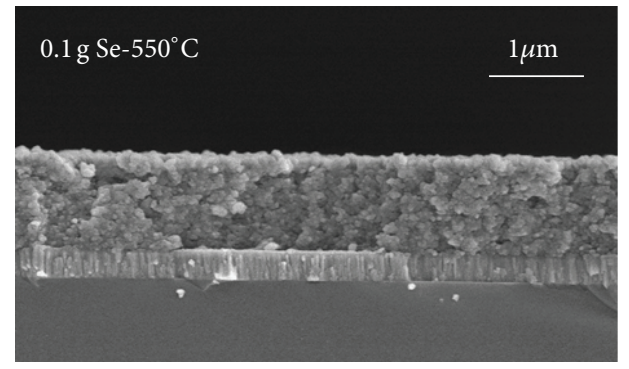

(b)

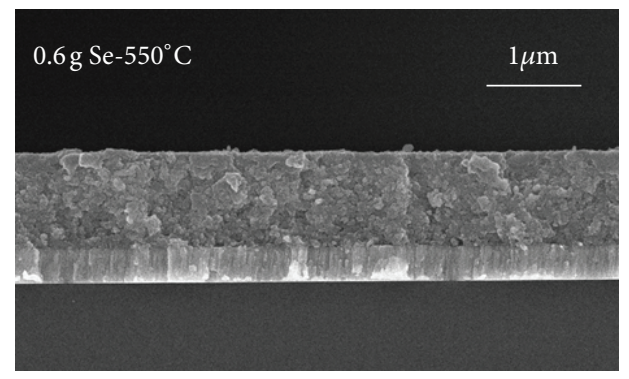

(d)

FIGURE 7: Cross-section observations of the CIS absorber layers as a function of extra Se content, the selenization temperature was $550^{\circ} \mathrm{C}$.

at less extra Se content have the better crystalline structure but will cause more pores. However, too much Se being used is not necessary because that will inhibit the grain growth and the crystallization of the CIS absorber layers.

Also, the cross morphologies of the CIS absorber layers as a function of extra Se content were also observed, and the results were compared in Figure 7. As no extra Se was put in the furnace $(0.0 \mathrm{~g})$, the pores were really observed in the cross-section. The porous structures are caused because the large grains grow at the expense of small ones, which result in the formation of new and larger voids where the small grains are originally located. However, the pores apparently decreased, and the absorber layers became more densified with increasing Se content. Those results prove again that 


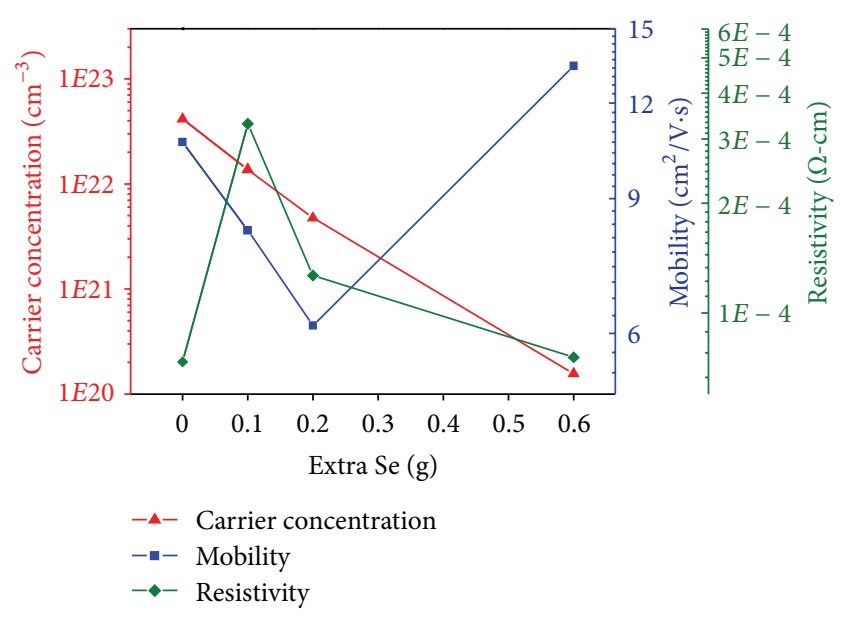

FIGURE 8: Resistivity $(\rho)$, hall mobility $(\mu)$, and carrier concentration $(n)$ of the CIS absorber layers as a function of extra Se content; the selenization temperature was $550^{\circ} \mathrm{C}$.

as the CIS absorber layers are densified and crystallized in a selenization furnace, the extra Se content has a more important effect to influence the films' characteristics than the selenization temperature.

Figure 8 shows the dependence of electrical properties of the CIS absorber layers on used extra Se content in the selenized process. The carrier concentration linearly decreased from $4.15 \times 10^{22} \mathrm{~cm}^{-3}$ to $1.57 \times 10^{20} \mathrm{~cm}^{-3}$ as extra Se content increased from $0.0 \mathrm{~g}$ to $0.6 \mathrm{~g}$, respectively. From the SEM surface and cross morphologies shown in Figures 6 and 7 , the crystallinity can decrease because too much extra Se content used in the selenization process will inhibit the crystallization of the CIS absorber layers, then the defects will increase, and the carrier concentration will decrease. Thus, the mobility had no apparent trend with the variation of extra Se content and had a maximum of $13.4 \mathrm{~cm}^{2} / \mathrm{V} \cdot \mathrm{s}$ at $0.6 \mathrm{~g}$. The minimum resistivity of the CIS absorber layers at extra Se content of $0.0 \mathrm{~g}$ is mainly caused by the mobility being at its maximum.

\section{Conclusions}

The CIS absorber layers were selenized in non-vacuum spray coating method. As $0.2 \mathrm{~g}$ extra Se content was used in the selenized process of the CIS absorber layers, the full width at half maximum (FWHM) value of the (112) peak decreased from 0.683 to 0.476 and the relative diffraction intensity of (112) peak had no apparent change as the selenization temperature increased from $450^{\circ} \mathrm{C}$ to $600^{\circ} \mathrm{C}$. The secondary CuSe phase was observed in the $600^{\circ} \mathrm{C}$-selenized CIS absorber layers. $0.367,0.481,0.565$, and 0.601 as extra Se content was $0.0 \mathrm{~g}, 0.1 \mathrm{~g}, 0.2 \mathrm{~g}$, and $0.6 \mathrm{~g}$, respectively. As $550^{\circ} \mathrm{C}$ was used in the selenized temperature of the CIS absorber layers, the full width at half maximum (FWHM) value of the (112) peak increased from 0.367 to 0.601 and the relative diffraction intensity of (112) peak also had no apparent change as the extra Se content increased from $0.0 \mathrm{~g}$ to $0.6 \mathrm{~g}$. The secondary CuSe phase was observed in the CIS absorber layers with extra $0.6 \mathrm{~g}$ content during the selenization process. This result suggested that the crystallinity decreased with increasing extra Se content used during the selenization process. This study proves that we have investigated a useful non-vacuum method to prepare CIS absorber layers with different crystallinity by controlling the selenization temperature and the extra Se content added in the selenization furnace for further solar cells' fabrication.

\section{Acknowledgments}

The authors acknowledge financial supports of Nanowin Technology Co., Ltd., NSC 102-2622-E-390 -002-CC3, and NSC 102-2221-E-390-027.

\section{References}

[1] M. I. Kabir, S. A. Shahahmadi, V. Lim et al., "Amorphous silicon single-junction thin-film solar cell exceeding $10 \%$ efficiency by design optimization," International Journal of Photoenergy, vol. 2012, Article ID 460919, 7 pages, 2012.

[2] A. Shah, J. Meier, A. Buechel et al., “Towards very low-cost mass production of thin-film silicon photovoltaic (PV) solar modules on glass," Thin Solid Films, vol. 502, no. 1-2, pp. 292-299, 2006.

[3] F. H. Wang, C. C. Huang, C. F. Yang, and H. T. Tzeng, "Optical and Electrical Properties of the Different Magnetron Sputter Power $300^{\circ} \mathrm{C}$-Deposited $\mathrm{Ga}_{2} \mathrm{O}_{3}-\mathrm{ZnO}$ Thin Films and Applications in $\mathrm{p}-\mathrm{i}-\mathrm{n} \alpha$-Si:H Thin-Film Solar Cells," International Journal of Photoenergy, vol. 2013, Article ID 270389, 7 pages, 2013.

[4] A. Romeo, M. Terheggen, D. Abou-Ras et al., "Development of thin-film $\mathrm{Cu}(\mathrm{In}, \mathrm{Ga}) \mathrm{Se}_{2}$ and CdTe solar cells," Progress in Photovoltaics, vol. 12, no. 2-3, pp. 93-111, 2004.

[5] Y. M. Shin, D. H. Shin, J. H. Kim, and B. T. Ahn, "Effect of Na doping using $\mathrm{Na} 2 \mathrm{~S}$ on the structure and photovoltaic properties of CIGS solar cells," Current Applied Physics, vol. 11, no. 1, pp. S59-S64, 2011.

[6] K. Ramanathan, J. Keane, and R. Noufi, "Properties of highefficiency CIGS thin-film solar cells," in Proceedings of the 31st IEEE Photovoltaic Specialists Conference, pp. 195-198, Lake Buena Vista, Fla, USA, January 2005.

[7] M. M. Islam, S. Ishizuka, A. Yamada et al., "CIGS solar cell with MBE-grown ZnS buffer layer," Solar Energy Materials and Solar Cells, vol. 93, no. 6-7, pp. 970-972, 2009.

[8] M. Powalla, G. Voorwinden, D. Hariskos, P. Jackson, and R. Kniese, "Highly efficient CIS solar cells and modules made by the co-evaporation process," Thin Solid Films, vol. 517, no. 7, pp. 2111-2114, 2009.

[9] C. Y. Hsu, P. C. Huang, Y. Y. Chen, and D. C. Wen, "Fabrication of a $\mathrm{Cu}(\mathrm{InGa}) \mathrm{Se}_{2}$ thin film photovoltaic absorber by rapid thermal annealing of $\mathrm{CuGa} / \mathrm{In}$ precursors coated with a Se layer," International Journal of Photoenergy, vol. 2013, Article ID 132105, 7 pages, 2013.

[10] S.-I. Gu, S.-H. Hong, H.-S. Shin et al., "Phase analysis of $\mathrm{Cu}\left(\mathrm{In}_{1-\mathrm{x}} \mathrm{Ga}_{\mathrm{x}}\right) \mathrm{Se}_{2}$ prepared by solvothermal method," Ceramics International, vol. 38, no. 1, pp. S521-S523, 2012.

[11] C. C. Wu and C. F. Yang, "Investigate the properties of nanostructured $\mathrm{Li}$-doped $\mathrm{NiO}$ films using the modified spray pyrolysis method," Nanoscale Research Letters, vol. 8, article 33, 2013. 
[12] Y. Igasaki and H. Saito, "Substrate temperature dependence of electrical properties of $\mathrm{ZnO}$ :Al epitaxial films on sapphire (1210)," Journal of Applied Physics, vol. 69, no. 4, pp. 2190-2195, 1991. 

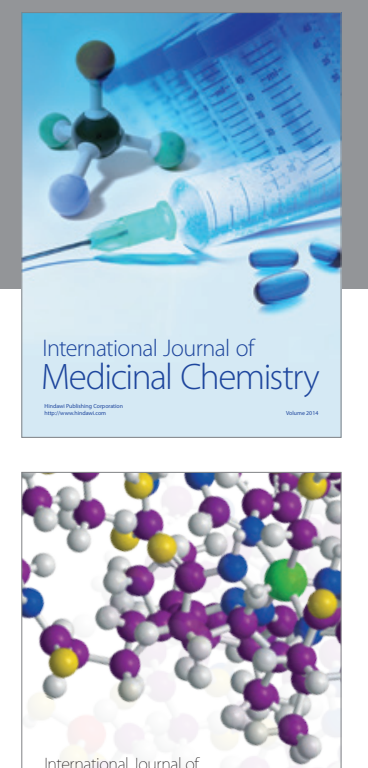

\section{Carbohydrate} Chemistry

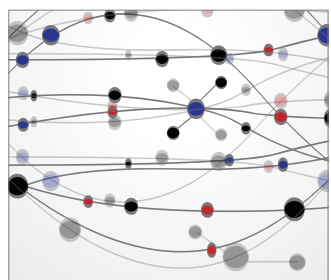

The Scientific World Journal
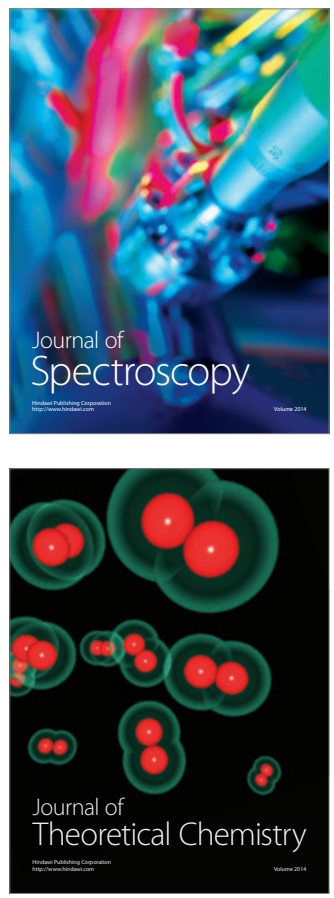
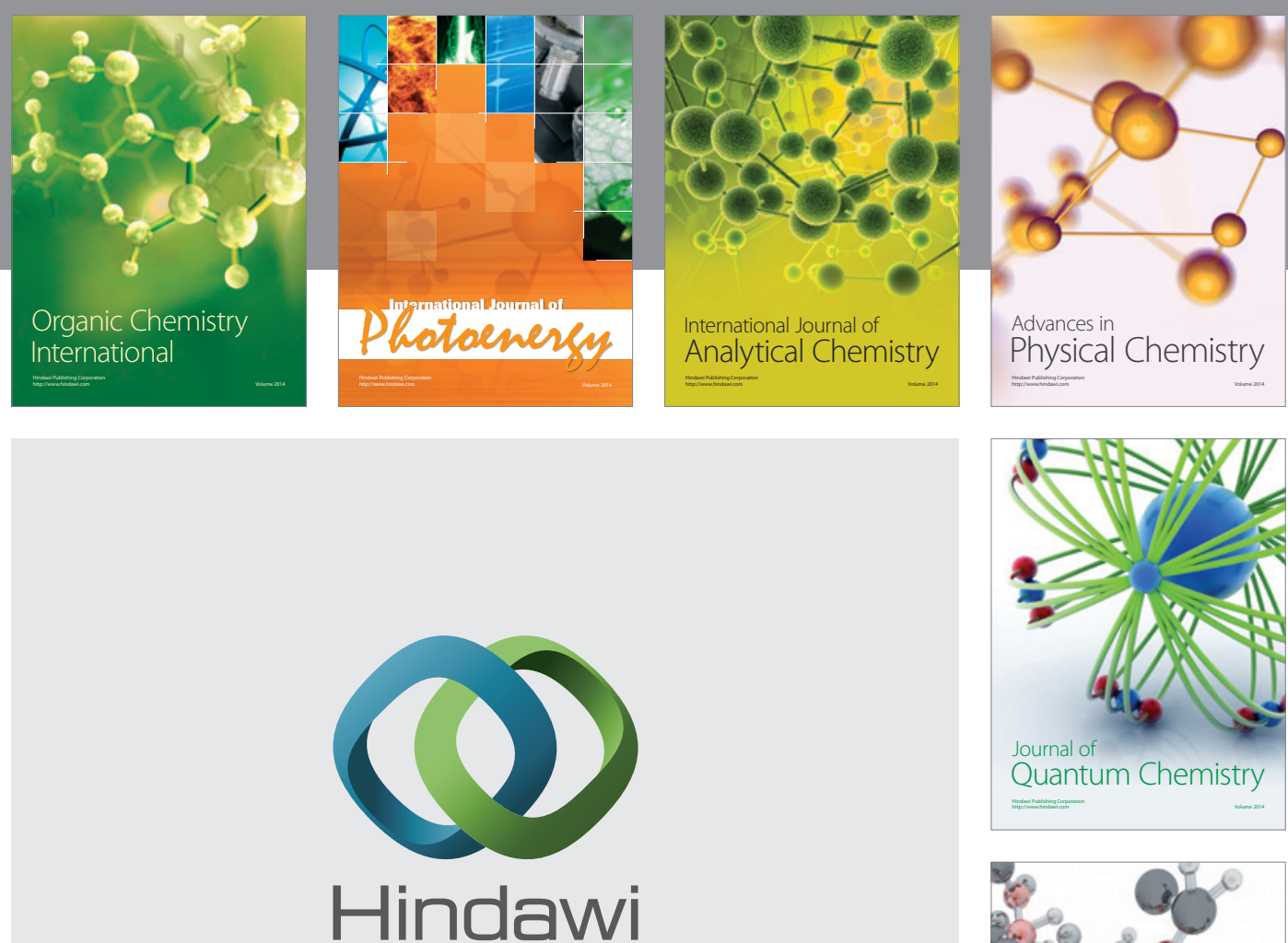

Submit your manuscripts at

http://www.hindawi.com

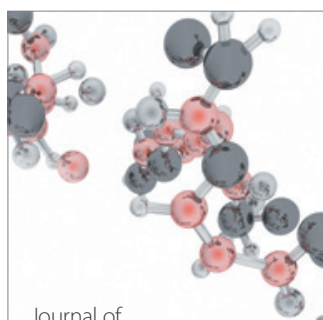

Analytical Methods

in Chemistry

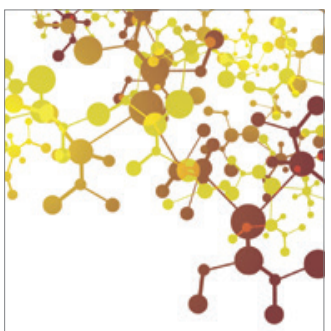

Journal of

Applied Chemistry

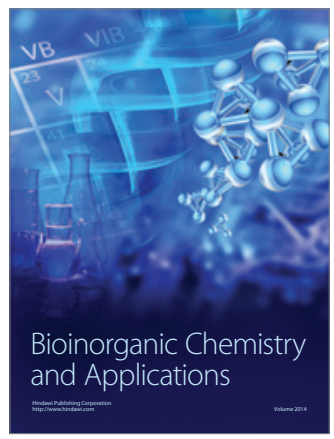

Inorganic Chemistry
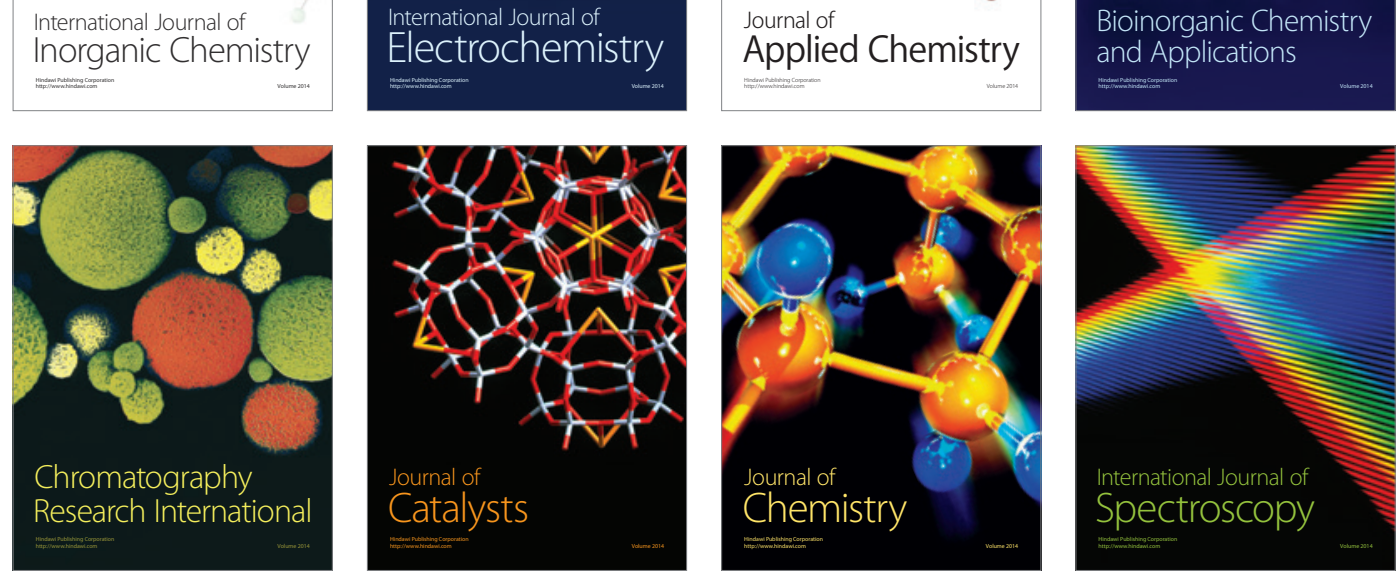